\title{
PRÁTICAS PEDAGÓGICAS E O DESENVOLVIMENTO DA RESPONSABILIDADE SOCIOAMBIENTAL NA COMUNIDADE ESCOLAR DO INSTITUTO ESTADUAL PROF. a NENA - CIEP DE SAPIRANGA - RS. ${ }^{1}$
}

\author{
Márcia Inês Rockenbach, Elisane Mạ Rampelotto \\ 'Trabalho de Conclusão do Curso Pós Graduação: Especialização em Educação Ambiental - Pólo \\ Universitário de Educação a Distância de Sapiranga - RS, apresentado a Universidade Federal de \\ Santa Maria - UFSM, como requisito parcial para a obtenção do título de Especialista em Educação \\ Ambiental.
}

\section{RESUMO}

O trabalho sobre as Práticas Pedagógicas e o Desenvolvimento da Responsabilidade Socioambiental na Comunidade Escolar do Instituto Estadual Prof.a NENA - CIEP de Sapiranga - RS. Inicialmente realizou-se um estudo para diagnosticar os principais problemas socioambientais, fizeram-se atividades de conscientização na escola, na comunidade e práticas ambientalmente sustentáveis. Para concluir realizou-se uma avaliação dos depoimentos dos participantes voluntários nas ações do estudo. O estudo objetiva-se em conscientizar a comunidade, identificar percepções a cerca da responsabilidade ambiental, desenvolver ações de orientação sobre ações sustentáveis. Justifica-se pela necessidade da conscientização ambiental em vista dos problemas ambientais que a comunidade escolar enfrenta. Participaram deste estudo, gestores, educadores, educandos e membros da comunidade escolar do Instituto Estadual Profa. NENA - CIEP. O método utilizado foi o qualitativo que trabalha com descrições e interpretações. O instrumento utilizado foi um estudo teórico e análise de depoimentos dos participantes, embasada na literatura sobre o assunto. Os resultados do estudo mostram que ainda não se tem uma consciência e responsabilidade ambiental, o que contribui para o agravamento de problemas ambientais no contexto socioambiental.

Palavras-Chaves: Responsabilidade Socioambiental, Práticas Pedagógicas, Sustentabilidade.

\section{ABSTRACT}

The work on the Pedagogical Practices and the Development of Environmental Responsibility in the Community School of the State Institute Professor. nd NENA - CIEP Sapiranga - RS. Initially we carried out a study to diagnose the key social and environmental problems, there have been awareness activities at school, community and environmentally sustainable practices. To complete an evaluation took place in the depositions of willing participants in the actions of the study. The study aims to raise awareness in the community, identify perceptions about environmental responsibility, develop initiatives for guidance on sustainable actions. Justified by the necessity of environmental awareness in view of environmental problems facing the school community. Participated in this study, managers, educators, students and school community members of the State Institute Professor. NENA - CIEP. The method used was qualitative work with descriptions and interpretations. The instrument used was a theoretical study and analysis of statements from the participants, based on the literature on the subject. The study results show that there is still not an 
environmental awareness and responsibility, which contributes to the worsening of environmental problems in the socio-environmental context.

Key Words: Environmental Responsibility, Pedagogical Practices, Sustainability.

\section{INTRODUÇÃO}

Ao observar as comunidades escolares, em especial à do Instituto Estadual Professora NENA - CIEP de Sapiranga - RS, percebe-se que as causas das agressões ao meio ambiente são de ordem política, econômica e cultural. A sociedade ainda desconhece a importância do meio ambiente e de sua preservação. Por isso, talvez, a preocupação com o meio ambiente caminha a passos lentos nesta e em outras comunidades. As carências nas mais variadas áreas impedem que sejam empregadas tecnologias/investimentos na área ambiental. As dificuldades sociais, econômicas, acabam contribuindo na intensificação dos problemas ambientais nesta comunidade escolar.

Esta Comunidade se formou no decorrer do auge produtivo do setor calçadista. Neste momento as autoridades municipais, não estavam preocupadas na organização da sociedade, mas apenas em trazer e disponibilizar mão de obra para a indústria calçadista. Esta Comunidade é um dos exemplos mais típicos da falta de infra-estrutura para os moradores do município de Sapiranga.

Os trabalhadores que vinham do interior do Rio Grande do Sul, Santa Catarina e Paraná, em sua maioria com poucos recursos e provenientes do setor primário de produção, foram invadindo esta comunidade. Em sua maior parte a área de ocupação era verde e de preservação permanente, por ser da encosta do Morro ${ }^{1}$ Ferrabráz.

Apesar da falta de disponibilidade de estrutura básica as pessoas foram se instalando e se fixando ali, constituindo assim a Vila Esperança. Nesta comunidade além da ocupação ilegal, há moradores em áreas ciliares, onde inclusive descartam o lixo no córrego, que por muitos é visto como depósito de lixos e entulhos.

Com a convivência na comunidade escolar percebe-se a urgência de ações, que visam à defesa do meio ambiente, não apenas no que se refere às áreas de preservação, mas em todas que estão sofrendo algum tipo de degradação.

A falta de preocupação em relação à preservação Ambiental permanece na comunidade de Sapiranguense, pois a grande maioria não faz a separação do lixo, e ainda muitas famílias depositam seus lixos nos córregos da cidade em vez de deixá-los na rua para que seja recolhido pelos lixeiros.

Embora estejam acontecendo ações a nível municipal, ainda são insuficientes para a solução dos problemas de degradação ambiental em nossa comunidade. Inicialmente acredita-se ser necessário desenvolver a responsabilidade e comprometimento coletivo visando ações efetivas, para erradicar ou ao menos amenizar os problemas nesta comunidade.

Neste sentido, este estudo se justifica pela importância de utilizar-se de vários elementos que possam auxiliar na identificação dos problemas que prejudicam o ambiente na comunidade escolar do Instituto Estadual Professora NENA - CIEP e possibilitar a elaboração de possíveis soluções para tal.

1 - Morro Ferrabráz - é morro que é o ponto turístico mais conhecido de Sapiranga, ficou conhecido nacionalmente como o local onde aconteceu a Batalha dos Muckers e atualmente acontecem os campeonato estadual e nacional de vôo livre. 
A questão ambiental é um dos assuntos que tem atraído atenção das pessoas, pela valorização que se dá à qualidade de vida e pela percepção de consequências do descaso com o Meio Ambiente tem conduzido às situações críticas para a própria humanidade. Ao pensar nessas questões percebe-se a necessidade de promover a Educação Ambiental na comunidade escolar do Instituto Estadual Prof. a NENA - CIEP, através da separação de resíduos sólidos e caminhada ecológica na encosta do morro Ferrabráz, na comunidade, que contribuiu para a elaboração do projeto "lixo zero", na escola e na comunidade.

A metodologia aplicada neste Trabalho de Especialização em Educação Ambiental procurou iniciar a pesquisa com levantamentos de referenciais teóricos para leituras e embasamentos a cerca do tema sobre a Importância da Preservação Ambiental para uma construção de um Futuro Sustentável. Estas leituras foram realizadas utilizando-se livros, artigos, PCNs, LDB e sites da Internet. Ainda, foi realizado levantamento bibliográfico de obras referentes à importância da Educação Ambiental no contexto educacional. Para fechar o estudo desenvolveu-se uma pesquisaação junto à comunidade para analisar as percepções dos educandos, educadores e membros da comunidade a cerca das ações desenvolvidas.

Assim, o trabalho objetiva a busca da conscientização dos educandos e da comunidade escolar com estudos e desenvolvimento de atividades benéficas ao Meio Ambiente. Através do desenvolvimento de atividades de conscientização na comunidade para a separação do lixo de forma que possa haver o reaproveitamento do lixo reciclável e orientação para que não haja depósito indevido. Visando sempre o trabalho e engajamento coletivo para obtenção de resultados efetivos e satisfatórios.

Neste contexto, cabe aos educadores um desfio espacial: "estimular e construir um mundo melhor" ou quem sabe "reconstruir", uma vez que, não por maldade, mas certamente por desconhecimento, cometemos sucessivos erros ambientais.

Assim em parceria com a comunidade escolar proponho um projeto onde à busca e as promoções das ações contemplem na totalidade a formação do ser como Humano de fato. Para tal incluirei também o aspecto cultural além das inter-relações pessoais, além do puramente ambiental. Estou convicta de que desta forma estar-se-à contribuindo, para construir um mundo melhor, para futuras gerações.

\section{APROXIMAÇÃO COM A COMUNIDADE ESCOLAR DO INSTITUTO ESTADUAL PROF. a NENA - CIEP}

Percebendo as demandas, dos moradores em torno da escola relacionadas à questão ambiental, permitiu a aproximação e o conhecimento das principais dificuldades encontradas por eles.

A aproximação com a comunidade escolar é desde 2005, quando iniciei minhas atividades docentes nesta Instituição, porém esta relação começou a se estreitar quando comecei as atividades junto ao Conselho Municipal de Assistência Social, o que possibilitou conhecer a realidade vivida e compreender as suas relações sociais, assim como encontrar um grupo de pessoas que mantivessem encontros periódicos.

Neste sentido, pode-se considerar que de acordo com Oliveira, 2000, p.27 "uma das dificuldades do pesquisador é a sua inserção e, ao mesmo tempo, a sua aceitação como pessoa estranha no meio de uma comunidade". A inserção é um processo pelo qual o pesquisador procura atenuar a distância que o separa do grupo social com que pretende trabalhar. Por isto, acredita-se que tais lideranças poderiam abrir as portas do bairro, para que pudesse estreitar a distância que separavame das pessoas da comunidade. 
A partir disto iniciaram-se as tentativas de aproximação e inserção no bairro através de pessoas que exerciam alguma liderança, nas seguintes entidades representativas: Associação de Moradores, O Instituo Estadual, O Atendimento sócio-econômico em meio-aberto e a Comunidade Católica São José Operário e a Comunidade Evangélica Luterana.

Algumas destas entidades não funcionavam enquanto um coletivo, sendo constituídas somente pelos seus representantes. Enfim, não possuíam um grupo engajado e nas poucas ações relacionadas às questões ambientais não havia a participação das pessoas da comunidade. Parecia que a luta diária pela sobrevivência constituía-se na maior prioridade das pessoas desta comunidade, as quais vivem num contexto de desigualdades e injustiças sociais tão marcantes.

Após muitos encontros frustrados e muitos questionamentos, pois não encontrava no bairro um grupo com o qual pudesse estabelecer contatos periódicos. Foi através das famílias atendidas no CRAS - Centro de Referência da Assistência Social, que pude estabelecer e estreitar ainda mais as relações na comunidade escolar.

O grupo de mães e crianças que se encontravam no local, ocupam-se com suas tarefas de confecção de acolchoados e outros artesanatos. As crianças permanecem na brinquedoteca. 0 grupo é estruturado, com encontros periódicos e muito receptivo, pois ao expor meu propósito fui acolhida no grupo. Havia finalmente encontrado o grupo para a realização de encontros.

No intuito de sensibilizar os participantes, no desenvolvimento das ações no contexto de mudanças de atitudes e conservação ambiental, é conveniente que a escola realize reuniões e encontros diversificados, para sensibilizar professores, alunos, funcionários e membros da comunidade usuária, discorrendo sobre as vantagens e perigos de práticas ambientais sustentáveis.

Considerando que para participar tem que conhecer, como ressalta a gestão democrática (PARO, 1997), a escola deve convidar especialistas em Educação Ambiental para iniciar o processo de sensibilização. Seria interessante fornecer dados para a discussão do assunto e aprofundar o conhecimento sobre a Educação ambiental e práticas ambientais sustentáveis. Após o grupo a ser trabalhado ter o entendimento de como seria realizada a práticas, e em que aspectos seriam utilizados seu resultado, pode-se dar início ao diagnóstico da realidade da comunidade escolar.

Essencialmente, esse é o ponto de partida e foi necessário coletar um conjunto comparável de informações que possibilitem levantar dados sobre a situação concreta da Comunidade Escolar. Os dados foram organizados de forma a viabilizar a geração de indicadores que permitiram formar base de interpretação para as ações ambientalmente corretas.

Após a coleta de informações sobre a situação das famílias em torno da escola, foram promovidos momentos de reflexão e debates na comunidade e na escola com os membros participantes do processo sobre as diversas dimensões abrangidas pela instituição, em um processo de sugestões de ações viáveis para a reversão do processo de degradação ambiental da estrutura natural nas proximidades da escola.

Acentua-se que, para o êxito desta etapa, a participação de todos os elementos participantes do processo se tornou fundamental. Necessitou-se de engajamento efetivo, com ações e práticas com as famílias e na escola, visando à mudança de hábitos na comunidade. 
ROCKENBACH \& RAMPELOTTO, vol.(4), $n^{\circ} 4$, p. 730-748, 2011. Monografias Ambientais (e-ISSN: 2236-1308)

REMOA

\section{Hipótese}

Ao implementar um projeto de educação para o ambiente, facilita-se aos alunos e à população uma compreensão fundamental dos problemas existentes, da presença humana no ambiente, da sua responsabilidade e do seu papel crítico como cidadãos de um país e de um planeta. Desenvolvemos assim, as competências e valores que conduzirão a repensar e avaliar de outra maneira as suas atitudes diárias e as suas conseqüências no meio ambiente em que vivem.

Destacar os conteúdos programáticos lecionados, para que se tornam uma das formas de tomada de consciência, disponibilizando-os de forma mais agradável e de maior aproveitamento.

A Educação Ambiental deve buscar valores que conduzam a uma convivência harmoniosa com o ambiente e as demais espécies que habitam o planeta, auxiliando o aluno a analisar criticamente o princípio antropocêntrico, que tem levado à destruição inconseqüente dos recursos naturais e de várias espécies.

\section{Projeto político pedagógico da escola}

O Projeto Político Pedagógico, é a oportunidade em que os professores e gestores, definam as direções pelas quais as ações escolares devem se orientar.

Assim, para a elaboração do Projeto Político Pedagógico do Instituto Estadual Prof.a NENA - CIEP, foram considerados vários autores que se destacam no sistema educacional, como Wigostky, Libâneo, Paulo Freire, sempre observando orientações e considerações específicas e gerais que são passadas pelas CREs aos Institutos Educacionais e os primeiros dias letivos são realizadas reuniões para que sejam feitas alterações e adaptações necessárias no nosso PPP, visando o melhor rendimento no processo de ensino-aprendizagem dos nossos educandos.

Pensar em Projeto Político Pedagógico para qualquer escola, pressupõe que os educadores tenham um espaço onde possam manifestar- se, que o processo da escola e suas experiências acumuladas sejam refletidos no texto. Que haja uma definição anterior sobre qual a concepção de Projeto Político Pedagógico será utilizada pelo grupo. A escola deve ser encarada como uma comunidade educativa que mobiliza o conjunto dos atores sociais e dos grupos profissionais em torno de um projeto comum. Para tal, é preciso demarcar os espaços próprios de ação, pois só na classificação desses limites se podem alicerçar uma colocação efetiva das práticas educativas.

Segundo a diretora da escola Olívia Stheigleder:

Projeto Político Pedagógico é a identidade da escola e da comunidade escolar. Ter uma identidade tem a ver com ter uma história, com poder colocar a própria realidade entre passado e futuro, integrando na realidade essa história e esse novo projeto, Se apostarmos na convivência sem segmentações, na coesão social e na solidariedade sem distâncias, tudo que leve a uma melhor identificação das escolas com seu território e sua diversidade social, e tudo aquilo que conduza a melhorar o sentido de identidade e de projeto comunitário, irá nesse caminho. 
ROCKENBACH \& RAMPELOTTO, vol.(4), ${ }^{\circ}$ 4, p. 730-748, 2011. Monografias Ambientais (e-ISSN: 2236-1308)

REMOA

Por isso destacamos a afirmação de Libâneo em nosso PPP, por que segundo ele:

\begin{abstract}
"Político por que diz respeito à arte e à ciência de governar - Ele prevê e dá uma direção à gestão da escola. Pedagógico por que diz respeito à reflexão sistemática sobre as práticas educativas: dá sentido e rumo às práticas educativas, contextualizadas culturalmente. 0 projeto representa a oportunidade de a direção, a coordenação pedagógica, os professores e a comunidade, tomarem sua escola nas mãos, definir seu papel estratégico na educação das crianças e jovens, organizar suas ações, visando a atingir os objetivos que se propõem. É o ordenador, o norteador da vida escolar". (Libâneo,2004,p.27).
\end{abstract}

O PPP da Escola tem como objetivo criar uma escola comunidade, um lugar no qual se trabalha modelos culturais, valores, normas e formas de conviver e de relacionar-se, neste âmbito em que esse conjunto de inter-relações e responsabilidades se materializa. As opções feitas na escola sobre avaliação, enturmação, horário de aulas, organização de festas seja a junina ou as Olimpíadas; enfim, cada decisão tomada pela escola é político-pedagógica e reflete as orientações pedagógicas assumidas pelos profissionais.

Fazendo a leitura do Projeto Político Pedagógico da escola pude observar a grande preocupação dos professores ao elaborá-lo, levando em consideração todos os aspectos que influenciam no sistema educacional e para que todas as áreas fossem bem explicitadas objetivando um sistema educacional inclusivo e participativo de um todo da comunidade escolar.

\title{
Metodologia
}

Esta monografia teve sua linha de pesquisa definida inicialmente como bibliográfica, além da pesquisa de campo, aproveitando-se de outros documentos que fazem parte da historicidade da escola investigada, que serviram de fonte de dados complementares, no intuito de atingir os objetivos aqui expressos. Estratégia esta comum em pesquisa, classificada por Yin (2001), como aplicação de projetos.

Como a pesquisa pretendeu levantar questões e hipóteses sobre modos e formas de aplicação de ações ambientalmente viáveis na comunidade escolar, optou-se por esta forma de estudo exploratório qualitativo, já que é apropriado para a efetividade da proposição de programas, planos e projetos a serem desenvolvidos, como é o caso da monografia (LAKATOS, 1995).

Como este estudo tinha o objetivo de desenvolver idéias sobre o tema das Práticas Pedagógicas e o desenvolvimento da Responsabilidade Socioambiental na Comunidade Escolar da Instituto Estadual Prof.a NENA - CIEP de Sapiranga - RS, teorizado como determinado fenômeno existente em concreto, explorou assim dados qualitativos para resolução da questão de pesquisa, por meio de sua acumulação, inicialmente não estruturados. Para Tripodi (1981), este procedimento posteriormente se refletirá em ações, na busca de descrição das sugestões através de análises empíricas e teóricas. Esta etapa foi desenvolvida com base em material já elaborado, constituído principalmente de livros e artigos científicos, da maneira como informa Gil (2002). As obras bibliográficas disponíveis foram, portanto, imprescindíveis para complementaridade do trabalho, pois se procurou reunir o maior número possível de fontes a que se teve acesso para a coleta de dados, atendendo as sugestões de Yin (2001).

O tempo necessário para a realização de cada uma das etapas desta tarefa, que procurou atender 
ao critério do realismo ${ }^{2}$, foi explicitado no Cronograma de ação em Projeto anterior à aplicação desta pesquisa. O trabalho teve caráter monográfico, que para Lakatos e Marconi $(1995$, p.151) é:

[...] um estudo sobre um tema específico ou particular de suficiente valor representativo e que obedece a rigorosa metodologia. Investiga determinado assunto não só em profundidade, mas em todos os seus ângulos e aspectos, dependendo dos fins a que se destina.

Os dados coletados na pesquisa bibliográfica foram tratados através do exame, da categorização e classificação (YIN, 2001). Nesta fase, optou-se pela análise de conteúdo que, segundo Roesch (1996), é a forma de interpretação dos dados através dos modelos conceituais pré-definidos. Este modelo de análise baseou-se em proposições teóricas, relacionando os objetivos do estudo com as revisões feitas na literatura e as possíveis interpretações que pudessem surgir. Teve o objetivo de organizar e classificar os dados, retirando deles repostas para o objetivo central da pesquisa, da forma como menciona Yin (2001).

A análise do conteúdo foi feita através da revisão das obras relacionadas ao tema da Educação ambiental e a Responsabilidade Socioambiental, comparando com os da teoria de autores e com a tendência na prática, no propósito de buscar a identificação de valores predominantes nas ações comuns da Comunidade Escolar em relação a preservação e a conservação ambiental da Comunidade.

Nos resultados buscou responder aos objetivos e propósitos do estudo, no sentido de definir as práticas que impulsionam em direção à avaliação estrutural da escola como resultado das ações do gestor, visando à eficiência da educação de qualidade. Em seguida, a análise procurou identificar as variáveis que compõem a avaliação da escola: os métodos, as técnicas, as funções, definindo a importância do papel do gestor nestas ações, com fundamento nos ensinamentos de Melchior (1998).

Constituiu categoria de análise nesta pesquisa, a visão tanto teórica quanto objetiva, sobre avaliação do desempenho do gestor enquanto caracterizador da estrutura da escola, com destaque para o processo de ensino e aprendizagem.

\section{Levantamento e verificação de dados}

O trabalho de pesquisa de campo realizado na Comunidade Escolar do Instituto Estadual Prof.a NENA - CIEP, no município de Sapiranga/RS constituiu-se de etapas a serem seguidas com dois grupos da comunidade escolar. Os segmentos de professores e alunos do segundo ano do ensino médio, foram convidados para a obtenção de dados e informações relativos às Ações didático pedagógicas, sob perspectiva do desenvolvimento de novos paradigmas e padrões culturais socioambientais, pelo entendimento de que formam a base da instituição educacional. 0 segundo grupo de membros da comunidade que foram convidados e foram voluntários para o desenvolvimento de encontros de orientação e oficinas de reciclagem. Todos participantes são descritos em seu depoimentos por nomenclaturas.

Inicialmente foram distribuídos entre professores e alunos, aqueles que se dispusera a colaborar

2 - O realismo é um movimento de estética literária, criada por Machado de Assis, que tem em sua essência a preocupação com a objetividade, a busca perene humana na drama da existência, um sentido para o encadeamento dos fatos e se revela no senso contemporâneo. 
com a pesquisa, para dar um depoimento sobre a temática da pesquisa, que posteriormente foram tabulados e fizeram parte da análise para a própria continuação da pesquisa, através dos encontros efetuados com o corpo docente e discente da instituição em foco. A amostra foi composta por 3 professores e 28 alunos.

Após a participação dos educandos, educadores e gestores com seu depoimento livre sobre a temática, participaram da caminhada ecológica, o que Ihes possibilitou reconhecer os problemas ambientais na comunidade.

$\mathrm{Na}$ continuidade das ações foram realizados encontros com as famílias atendidas no Centro de Referência da Assistência Social, as quais inicialmente receberam orientação da importância da separação e reciclagem do lixo, após foram desenvolvidas atividades de artesanato a partir de materiais recicláveis. Após participaram de uma avaliação destes encontros e atividades, através de seus depoimentos.

\section{A EDUCAÇÃO AMBIENTAL E SUA IMPORTÂNCIA NO CURRÍCULO ESCOLAR.}

Atualmente as questões ambientais têm adquirido maior importância, em virtude das mudanças que o mundo vem sofrendo, a partir da crise da modernidade, também acentuaram-se os números de estudos, pesquisas e trabalhos na busca de soluções para os problemas sociais, ambientais, políticos e econômicos os quais estamos vivenciando cotidianamente. Assim começam a surgir novos paradigmas que visam uma direção mais sistêmica e complexa de sociedade.

Neste sentido, podemos partir da Conferência de Estocolmo, em 1972 que ampliou o conceito de Educação Ambiental, bem como a Conferência de Tibilisi, que em 1977, reconheceu internacionalmente que:

A Educação Ambiental é um processo de reconhecimento de valores e clarificação de conceitos, objetivando o desenvolvimento das habilidades e modificando as atitudes em relação ao meio, para entender e apreciar as inter-relações entre os seres humanos, suas culturas e seus meios biofísicos. A Educação Ambiental também está relacionada com a prática das tomadas de decisões e a ética que conduzem para a melhoria da qualidade de vida. (SATO, 2002: 23-24).

Foi a partir da Conferência de Tibilisi, que se desenvolveu, no mundo inteiro, a percepção de que o futuro de nossa sociedade, enquanto homens e mulheres dependem das relações estabelecidas entre os homens e os recursos naturais. Neste contexto inicialmente, a Educação Ambiental, era apresentada sob perspectivas preservacionistas, com suas ações planejadas e voltadas para o cuidado com a natureza. Porém hoje já podemos ver que esta não apenas se limita a simples modificações ambientais, mas já vem incluindo na estrutura social com um caráter social e político, uma vez que o ambiente é um todo complexo - sociedade humana, mais a natureza.

Neste contexto, a Educação Ambiental vem se destacando e cada vez mais lhe é atribuído sua importância, sendo que hoje já se torna conveniente e fundamental que os currículos escolares busquem e desenvolvam práticas pedagógicas sob aspectos orientados ao ambiente local. Com isso, assuntos como ética, estética, respeito e cidadania planetária devem integrar os debates e as atividades da rotina da sala de aula.

Segundo Moraes (2001), a escola continua fragmentando o conhecimento em especialidades, a super valorização do conteúdo em detrimento ao processo de construção de conhecimento, 
ratificados em metodologia e currículos rígidos, restando aos alunos obediência e submissão. Neste sentido, os educadores assumem um desafio que vem criando cada vez dimensões mais amplas, em vista que:

O conhecimento humano é adquirido pelo indivíduo por meio da transmissão estruturadora do processo ensino-aprendizagem, e o sujeito têm um papel insignificante em sua aquisição e em sua elaboração. A educação, na maioria das vezes, é compreendida como instrução e está circunscrita à ação da escola. A ênfase é dada às situações de sala de aula, nas quais os alunos são instruídos pelos professores. (MORAES 2001, p.51)

Ainda, torna-se fundamental observarmos que, segundo Moraes (2001, p.53) é necessário fugir do que vêm sendo utilizados pela grande maioria das escolas como versões computadorizadas - a substituição da educação burguesa, que na verdade "é apenas uma imagem de uma técnica social de dominação".

Portanto, sob perspectiva educativa, a Educação Ambiental, pode ser desenvolvida como eixo transversal e interdisciplinar, uma vez que esta permite a análise dos mais variados temas que enfocam as relações entre a humanidade, o meio natural e as relações sociais, sem que se percam as especificidades de cada disciplina.

Com isso torna se necessário ter clareza que a Educação Ambiental não deve ser apenas mais uma disciplina no currículo escolar, porque esta não se destina como uma disciplina fechada, mas sim como um tema/eixo que permeia todas as relações e atividades escolares, buscando principalmente desenvolver-se de maneira interdisciplinar, conforme preconiza o Plano Nacional de Educação Ambiental - Lei 9.795/99, que estabelece:

\footnotetext{
Art. 10 Entendem-se por educação ambiental os processos por meio dos quais o indivíduo e a coletividade constroem valores sociais, conhecimentos, habilidades, atitudes e competências voltadas para a conservação do meio ambiente, bem de uso comum do povo, essencial à sadia qualidade de vida e sua sustentabilidade.

Art. 2ㅇ A educação ambiental é um componente essencial e permanente da educação nacional, devendo estar presente, de forma articulada, em todos os níveis e modalidades do processo educativo, em caráter formal e não-formal.
}

Neste sentido, podemos definir a educação ambiental como meio de compreender a natureza e as complexidades do meio ambiente e interpretar a interdependência entre os diversos elementos que conforme o ambiente, com vistas a utilizar racionalmente os recursos do meio na satisfação material e espiritual da sociedade no presente e no futuro. Ainda, deve capacitar ao pleno exercício da cidadania através da formação de uma base conceitual abrangente, técnica e culturalmente capaz de permitir a suspensão dos obstáculos à sustentabilidade.

\section{A Importância da educação ambiental nos currículos escolares, nos paradigmas da contemporaneidade.}

Os problemas ambientais têm a ver com o nosso modo de vida e para resolvê-los é necessário mudar hábitos de consumo. $\mathrm{O}$ atual modelo de desenvolvimento trouxe benefícios e bem-estar, e é difícil à maioria abrir mão de serviços e produtos com os quais os avós nem sonhavam quando eram jovens.

O educador como profissional reflexivo, de acordo com Carvalho, (2004) tem sua confluência com 
o vitalismo e o pragmatismo de John Dewey: devemos dar mais importância às conseqüências e efeitos da ação do que a seus princípios e pressupostos, o critério da verdade deve ser encontrado nos efeitos e conseqüências de uma idéia, em sua eficácia, em seu sucesso. Neste sentido, o/a professor/a deve rever suas práticas, as quais devem contemplar a construção de novos valores e padrões de consumo, que viabilizem o desenvolvimento sustentável.

Podemos destacar neste sentido, a abordagem tradicional da Educação Ambiental apontada por Guimarães (2004), que foca a realização da ação educativa na terminalidade da ação, compreendendo ser essa terminalidade o conhecimento retido e, no caso da formação de professores/as, a supervalorização da prática em detrimento dos fundamentos norteadores da política e da ética.

Nesta tendência tradicional ou convencional da educação ambiental e da formação, privilegia-se o aspecto cognitivo e prático do processo educativo e acredita que o conhecimento reflexivo do educador isolado sobre sua prática pedagógica irá repercutir sobre sua ação educativa, na escola e na sociedade. Nesse caso, é mais considerada no processo de aprendizagem a racionalidade cognitiva e instrumental do que a emoção, o conhecimento é reduzido à reflexão, sem considerar a prática socioambiental, em detrimento da multidimensionalidade, a objetividade com ênfase no individualismo, em detrimento da formação da subjetividade, da ação coletiva e da inserção sóciopolítico.

A Educação Ambiental crítica, encontra aporte nessa tendência pelos seus pressupostos teóricos e metodológicos, trazendo a sua especificidade, como alerta Carvalho, (2004, p. 17),

[...] da prática educativa ambientalmente orientada, de processos educativos que compreendam a interdependência entre sociedade-natureza e intervenham nos problemas e conflitos socioambientais. Essa práxis educativa em que a conscientização é compreendida como uma reflexão-ação, supera os ideais de conscientização ecológica do ambientalismo dos anos 70, em que práticas educativas eram instrumentos de suas ações, com a idéia central de "conhecer para preservar"; propõe uma mudança de valores e de atitudes na formação dos sujeitos por meio do seu engajamento ativo. A militância aqui poderia ser considerada um contexto ativo de formação desses/as educadores/as, com uma leitura crítica, problematizada e contextualizada da realidade educativa e socioambiental estudada.

Portanto o educador, considerando o tornar o pedagógico mais político e o político mais pedagógico é uma síntese expressiva dessa tendência. Cabe aqui a responsabilidade sobre o conteúdo dos que ensinam, como ensinam e o que movimenta suas lutas, superando dicotomias entre a teoria e a prática, o pessoal e o coletivo, o local e o global.

A formação em Educação Ambiental, então, passa a ser compreendida como uma rede de contextos que, desde a formação inicial, estendendo-se à vivência, à atuação profissional, à participação em cursos, grupos e eventos, são compreendidos como espaços/tempos de formação. Para isso, são fundamentais as políticas de Educação Ambiental reforçam a abordagem interdisciplinar, evoluindo para a compreensão do meio ambiente como tema transversal, assim como sugerem as diretrizes elaboradas pelo Ministério da Educação em 1997: os Parâmetros Curriculares Nacionais (PCNs).

Neste sentido, é importante consideramos a Lei no. 394, de 20 de dezembro de 1996, a nova Lei de Diretrizes e Base, que incide sobre a educação básica e a educação profissional, não menciona em seu texto a Educação Ambiental e a profissionalização docente, e a reforma educacional é sustentada, em seu texto, pela noção de competência. 
Esta tendência do educador como profissional competente é explicitamente marcada tanto na LDB como nos PCNs. $\mathrm{O}$ argumento desses documentos passa pela habilidade da produção empírica, de resultados desejáveis e aprovada socialmente, com otimização máxima de recursos humanos e materiais.

No desenvolvimento dos novos paradigmas e concepções educacionais, destaca se também a concepção de Carvalho, (2004), o profissional só é competente quando atinge objetivos sob certas condições; a fixação de competências, o acompanhamento e a avaliação são normas inerentes ao perfil almejado.

Nesse caso, defende-se a emergência de um novo paradigma no processo de ensinoaprendizagem, para uma formação crítica e emancipadora, racionalmente menos exigente mais expressiva na atuação dos educadores em práticas educativas comprometidas com o meio ambiente, com a sustentabilidade local e planetária, menos dogmática ao analisar o meio ambiente e mais coletiva nas intervenções, desenvolvendo um trabalho educativo para um saber solidário do conhecimento-emancipação.

\section{TEORIAS X PRÁTICAS NO CONTEXTO ESCOLAR E COMUNIDADE ESCOLAR: RELATO DA INVESTIGAÇÃO.}

Aqui foram analisados, à luz do que foi exposto nos capítulos anteriores, o depoimento dado por pessoas, educadores e educandos envolvidos no processo das ações didático-pedagógicas, para fins de conscientização da comunidade para ações efetivas para a concretização da sustentabilidade. Para tanto, aqui, serão apresentados os resultados obtidos através da pesquisa realizada, assim como, uma análise dos dados e uma posterior conclusão dos resultados obtidos através das ações na escola e comunidade escolar.

Com a transcrição dos depoimentos ${ }^{3}$, observa-se que os participantes e voluntários na participação do estudo, apresentam uma preocupação a cerca dos problemas ambientais e com a intensidade que estão crescendo na sociedade.

A tendência pela conscientização quanto à necessidade da preservação dos ambientes locais e naturais, passam a ser uma prioridade da sociedade, pois estes espaços por eles ocupados e a falta de cuidados ambientais acabam por acarretar problemas sociais graves. Assim faz-se necessário o planejamento para a superação dos problemas.

Refletir e repensar os princípios da educação ambiental e ações que regem uma instituição educacional, pode ser o primeiro passo para transformá-la. Pois se exige discuti-la em conjunto: valores, organização curricular, preceitos metodológicos, visão política e comunitária. Ao discutir a prática da educação Ambiental, cada professor/educador(a) enuncia concepções próprias acerca da vida, da educação, do educando[...]. (Participante $\mathrm{XY1).}$

Neste sentido, torna-se indispensável um trabalho de educação em questões ambientais, não apenas como um eixo interdisciplinar, mas sim como uma disciplina, com o fim de favorecer a formação de uma opinião pública bem informada e uma conduta dos indivíduos/cidadãos

3 - Foi solicitado aos voluntários que dessem seu depoimento, frente à sua preocupação com a sustentabilidade, e ações didáticas pedagógicas de educação ambiental nas comunidades com problemas ambientais. 
ROCKENBACH \& RAMPELOTTO, vol.(4), ${ }^{\circ}$ 4, p. 730-748, 2011. Monografias Ambientais $\quad$ (e-ISSN: 2236-1308)

REMOA

inspirada no sentido de sua responsabilidade para com a proteção e melhora do meio ambiente em toda a sua dimensão humana.

[...] Percebo a grande maioria dos educadores, encontram-se cercados por concepções metodológicas conteudistas, esquecem ou anulam-se no processo de ensino/aprendizagem sob as concepções no que referem ao contexto da sustentabilidade ambiental. Como membro desta comunidade escolar e educadora, percebo o quanto é necessário "desafiar o mito" da concepção conteudista, que reduz a educação ambiental e ambientalidade aos educadores das ciências naturais, permitindo assim a esta apenas a parcialidade, em vez do seu conjunto.[...](Idem).

Assim, percebe-se que os educadores sentem a necessidade e a urgência em desenvolver atividades e ações de Educação Ambiental, visto que nosso sistema educacional ainda se mantém vinculado a estrutura conteudista e teórica, não visando o desenvolvimentos de valores socioambientais do educando.

Diante da realidade com a qual nos deparamos muitas vezes a prática da educação ambiental não surte o efeito esperado, visto que a motivação é apenas momentânea. Tomada à iniciativa de realização de alguma ação relacionada ao meio ambiente, não há o acompanhamento posterior necessário.

Neste sentido, observa-se a preocupação do educando:

Como educando, penso que a Educação Ambiental, para ter uma mudança de paradigmas sociais deve ser desenvolvida de maneira contínua, no dia-a-dia da sala de aula. Ela deve servir como um instrumento de desenvolvimento de uma nova cultura que tenha como princípios básicos a sustentabilidade.[...]. (participante KG 1).

Assim, observa-se que o educando percebe-se que em sua grade curricular falta a Educação ambiental, para que possa permear e conhecer as especificidades dos problemas e contextos socioambientais. Para se preservar o ambiente e ter resultados efetivos é preciso que toda a sociedade colabore e participe da construção de uma mudança de mentalidade e consequentemente de hábitos em relação à problemática ambiental. Tal conscientização não se dará de um dia para outro, mas através de um trabalho constante de Educação Ambiental que garanta o envolvimento e a participação de todos: a escola, a família, a comunidade e o estado.

A Educação Ambiental sozinha não é suficiente para resolver os problemas ambientais, mas é a condição indispensável para tanto. A grande importância da Educação Ambiental é contribuir para a formação de cidadãos conscientes do seu papel na preservação do meio ambiente e apto para tomar decisões sobre questões ambientais necessárias para o desenvolvimento de uma sociedade sustentável.

Neste sentido é importante, despertar a importância das ações coletivas e levar o educando a realizar tarefas em sua própria comunidade, como afirma o educando: 
ROCKENBACH \& RAMPELOTTO, vol.(4), ${ }^{\circ}$ 4, p. 730-748, 2011. Monografias Ambientais (e-ISSN: 2236-1308)

REMOA

\begin{abstract}
Vejo a importância de participar de atividades que envolvam a Comunidade Escolar como um todo, pois possibilita a Comunidade perceber a escola como parte da comunidade, bem como do seu verdadeiro papel. Atividades como está deveriam ser desenvolvidas mais amplamente, em todos os segmentos da comunidade a fim de que estes percebam a escola como meio viável e agente da comunidade; e não apenas como espaço de junção de crianças e jovens sem compromissos e responsabilidades[...]. Através de observações e anotações constantes das atividades trabalhadas, podem-se identificar as principais causas e problemas que temos em nossa comunidade. Esta é a oportunidade suprema que teremos para iniciar e conscientizar a nossa comunidade da importância da nossa escola e de suas ações, bem como mudar a sociedade sob uma perspectiva de construir ações e uma nova cultura ambientalmente correta em nossa Comunidade. (Participante JFS).
\end{abstract}

Portanto, segundo o educando podemos observar que ao proporcionar em âmbito escolar, palestras e debates com moradores locais, possibilita um relato de experiências de vida e da história ambiental local, contribuindo para realizar um diagnóstico e desenvolver ações, para viabilizar maior responsabilidade ambiental.

Assim a preocupação da gestora, demonstra frente às dificuldades enfrentadas para viabilizar e conscientizar os educandos e comunidade escolar para integrarem as ações propostas pela escola:

Sei que nas últimas décadas, vêm se intensificando as preocupações relacionadas às questões ambientais e, juntamente com isso, as iniciativas de variados setores da sociedade para o desenvolvimento de atividades e projetos no intuito de educar as comunidades, procurando sensibilizá-las e mobilizá-las para a modificação de atitudes e apropriação de posturas que sejam benéficas ao seu equilíbrio.[...] (Participante HHK).

Observa-se que conforme o participante as questões ambientais estão permeando a preocupação em todas as instancias sociais e a escola como formadora de opinião deveria ter ações efetivas e continuadas de Educação Ambiental, visando à formação da responsabilidade ambiental do educando/cidadão.

[...]Tendo em vista esses aspectos citados anteriormente é necessário ter consciência de que a presença, em todas as práticas educativas, de reflexão sobre as relações dos seres entre si, do ser humano com ele mesmo e do ser humano com seus semelhantes é condição imprescindível para que a Educação Ambiental ocorra e dentro desse contexto, sobressaem-se as escolas, como sendo espaços privilegiados na inserção de atividades que propiciem essa reflexão, pois isso necessita de atividades de sala de aula e atividades de campo, com ações orientadas em projetos e em processos de participação que levem à autoconfiança, a atitudes positivas e ao comprometimento pessoal com a proteção ambiental implementados de modo interdisciplinar.[...] (Idem).

Assim, entende-se por educação ambiental, uma oportunidade da educação que privilegia uma compreensão dos ambientes de maneira não excludente, não maniqueísta. Ou seja, que privilegia as relações entre sociedade, ambiente, indivíduo e o grupo, buscando na reapropriação da natureza pelo homem a reconstrução dos valores em ambos. 
ROCKENBACH \& RAMPELOTTO, vol.(4), ${ }^{\circ}$ 4, p. 730-748, 2011. Monografias Ambientais (e-ISSN: 2236-1308)

REMOA

[...] O desenvolvimento de um processo de sensibilização da comunidade escolar pode fomentar iniciativas que transcendam o ambiente educacional, atingindo tanto o bairro no qual a escola está inserida como comunidades mais afastadas nas quais residam alunos, professores e funcionários que são potenciais multiplicadores de informações e atividades relacionadas à Educação Ambiental oferecida na escola e ainda podemos afirmar que o estreitamento das relações intra e extra-escolar é bastante útil na conservação do ambiente, principalmente o ambiente da escola e ainda sugere-se, entre outras propostas, que os trabalhos relacionados à Educação Ambiental na escola devem ter, como objetivos, a sensibilização e a conscientização; a busca de uma mudança comportamental, a formação de um cidadão mais atuante, a criação de condições para que a Educação Ambiental seja um processo contínuo e permanente, através de ações interdisciplinares; a integração entre escola e comunidade, objetivando a proteção ambiental.[...] (Idem).

Portanto, nessa particularidade da educação ambiental, deve-se buscar a sua efetivação tanto no ensino formal, desenvolvendo-se nos currículos das instituições públicas e privadas, como no ensino não-formal, através de ações e práticas educativas voltadas para a conscientização e orientação dos educandos no tocante à defesa do meio ambiente.

[...]Portanto devem-se buscar alternativas que promovam uma contínua reflexão que culmine em uma mudança de mentalidade, pois apenas dessa forma, conseguiremos implantar, em nossas escolas a verdadeira Educação Ambiental com atividades e projetos que serão frutos da ânsia de toda a comunidade escolar em construir um futuro com o qual possamos viver em um ambiente equilibrado, em harmonia com o meio, com os outros seres vivos e com nossos semelhantes. Concluiria que todas as atividades, que estão sendo desenvolvidos em nossa escola e comunidade escolar ainda são passos pequenos, poderia até dizer que apenas estamos apenas engatinhando, no que se refere a educação ambiental efetiva. Para daí sim afirmar que teremos mudanças de hábitos ambientais, bem como uma sustentabilidade do nosso desenvolvimento. (Idem).

Assim, é imprescindível que as pessoas percebam a necessidade de uma mudança de hábitos, principalmente de consumo, pois os recursos naturais são finitos e a qualidade destes depende destes hábitos.

A resolução definitiva da problemática ambiental não depende unicamente de um conjunto de normas, regras, leis, ou qualquer outro instrumento compulsório que seja. Por razão muito singela, os homens fazem as leis, mas as leis não fazem os homens. É uma solução que passa, fundamentalmente, pela tomada de consciência da ação do homem sobre o meio que habita. E não há outro caminho eficaz a percorrer que não seja o da educação. (Assmann, 1999, p.3).

Neste sentido, são importante que sejam desenvolvidos projetos e ações que viabilizem a conscientização e o respeito com o meio em que vivem e assim pode se observar que segundo o depoimento do educando que afirma: 
ROCKENBACH \& RAMPELOTTO, vol.(4), ${ }^{\circ}$ 4, p. 730-748, 2011. Monografias Ambientais (e-ISSN: 2236-1308)

REMOA

Falar das atividades do Projeto de Educação Ambiental, em nossa comunidade escolar é um privilégio, uma vez que nos deparamos com tantas dificuldades e problemas socioambientais em nossa comunidade. As ações que desenvolvemos e continuamos a desenvolver, relacionadas com o desenvolvimento de atividades, que viabilizam o resgate de valores socioambientais em nossa comunidade, vem de encontro com a demanda da nossa comunidade. Pois ali nos deparamos com muitos lixos depositados indevidamente, inclusive no nosso córrego, descarte de matérias de construção e industriais nos terrenos baldios e nas áreas públicas. As mobilizações e atividades que desenvolvemos na escola e comunidade, já estão contribuindo com a solução de parte de nossos problemas, pois se observou que a maioria da comunidade não reciclada o lixo de sua casa, e ainda pior largavam no córrego. E após oficinas na escola, além de não mais depositarem lixos indevidamente, já estão fazendo artesanato a partir dos materiais separados. (Participante kkll).

Assim, entende-se que a Educação Ambiental deve ser continuada e permanente, com tomada de consciência de sua realidade global, reconhecendo o tipo de relações que os homens estabelecem entre si com o meio, detectando problemas derivados a partir desta convivência. Mediante a prática que vise vincular o educando com a comunidade, com seus valores e ações, que possibilite o desenvolvimento de um comportamento que busque a transformação desta realidade sob aspectos ambientais e sociais.

Conforme integrante da comunidade escolar, já demonstra sua preocupação, como falta de vinculação da comunidade com a escola, onde os alunos não se empreendem em aplicar conhecimentos e ações em sua própria comunidade.

Quando a professora veio no CRAS, conversar conosco, propondo as ações de Educação Ambiental, achei que fosse mais uma dessas ações que não resultariam em nada, que não teriam continuidade, até por que a maioria não demonstrou interesse. Nos primeiros encontros tivemos poucos participantes e ainda sem interesse. Na medida em que fomos nos encontrando e nos foi proposto que teríamos oficina de artesanato com materiais recicláveis, que tivemos a participação de mais algumas senhoras. Na participação das oficinas tivemos a oportunidade de aproveitar materiais que antes nós colocávamos no lixo, hoje inclusive já consigo uma renda extra, com estes materiais que eu transformo em artesanato. (Participante JJB).

Segundo a moradora, percebe-se que a comunidade apesar de seu filho estudar na escola, não possuem laços e nem conhecem as ações da escola e a própria escola muitas vezes acaba não incentivando uma aproximação entre ambas. Os membros mais humildes reconhecem muitas vezes como inacessíveis pela falta de vinculo.

Neste sentido, ações conjuntas contribuem para a aproximação de ambas, fortalecem as ações. Ainda, oferece alternativas que viabilize o resgate da cidadania e renda alternativa aos membros da comunidade, bem como contribui para ações ambientalmente viáveis.

Eu como moradora da comunidade escolar, percebo que com as ações dos alunos na comunidade distribuindo folhetos para separar o lixo, e eles incentivados na escola acabam cobrando estas ações em casa, contribuiu para reduzir os lixos jogados nas ruas. Quando minha vizinha me convidou para participar da oficina de materiais recicláveis, pude ver na prática o quanto estás ações são importantes em nossa comunidade, porém deveríamos ter mais ações neste sentido e de forma continua, pois iria contribuir para a redução do acumulo de lixo inclusive no nosso córrego. (Participante GGT).

Assim, percebe-se que procedimentos responsáveis dentro da perspectiva de mudança de hábitos têm então maior potencial de sucesso com o uso de alternativas que dêem visibilidade as ações 
inteligentes de consumo e separação do lixo. Portanto, a responsabilidade social se desenvolve, identificando os problemas e buscando alternativas e possibilidades de ações continuadas para viabilizar a sancionar as dificuldades.

\begin{abstract}
Como moradora da comunidade, foi à primeira vez que participei de uma ação ambiental. Mas fiquei surpresa, pois das pessoas que participaram das reuniões, sequer sabia separar de forma adequada o lixo. Estas ações vêm ao encontro do nosso problema, pois temos muitos lugares que as pessoas largam o lixo, e depois são vitimas do seu próprio lixo, quando a água invade a suas casas e dias de chuvas intensas. Assim, acho que deve se dar continuidade e intensificar as ações para que não precisemos passar por este problema. (Participante CXX).
\end{abstract}

Segundo a moradora observa-se que ainda individuais que não sabem separa adequadamente o lixo, outros tão pouco, possuem uma preocupação efetiva frente os problemas ambientais que a sociedade vem enfrentando.

Neste sentido, tornam se fundamental realização de parcerias, ações e projetos que viabilizam orientação e práticas educativas que resgatem valores ambientais e que desperte a responsabilidade ambiental. E com o aumento dos desastres e problemas ambientais vê-se que estas ações tem urgência.

\title{
CONSIDERAÇÕES FINAIS
}

A escola é o espaço social e o local onde o aluno dará seqüência ao seu processo de socialização. 0 que nela se faz se diz e se valoriza representa um exemplo daquilo que a sociedade deseja e aprova. Comportamentos ambientalmente corretos devem ser aprendidos na prática, no cotidiano da vida escolar, contribuindo para a formação de cidadãos responsável.

Considerando a importância da temática ambiental e a visão integrada do mundo, no tempo e no espaço, a escola deverá oferecer meios efetivos para que cada aluno compreenda os fenômenos naturais, as ações humanas e sua conseqüência para consigo, para sua própria espécie, para os outros seres vivos e o ambiente. É fundamental que cada aluno desenvolva as suas potencialidades e adote posturas pessoais e comportamentos sociais construtivos, colaborando para a construção de uma sociedade socialmente justa, em um ambiente saudável.

Com os conteúdos ambientais permeando todas as disciplinas do currículo e contextualizados com a realidade da comunidade, a escola ajudará o aluno a perceber a correlação dos fatos e a ter uma visão holística, ou seja, integral do mundo em que vive. Para isso a Educação Ambiental deve ser abordada de forma sistemática e transversal, em todos os níveis de ensino, assegurando a presença da dimensão ambiental de forma interdisciplinar nos currículos das diversas disciplinas e das atividades escolares.

A fundamentação teórico/prática dos projetos ocorrerá por intermédio do estudo de temas geradores que englobam palestras, oficinas e saídas a campo. Esse processo oferece subsídios aos professores para atuarem de maneira a englobar toda a comunidade escolar e do bairro na coleta de dados para resgatar a história da área para, enfim, conhecer seu meio e levantar os problemas ambientais.

Portanto, dentro da Educação ambiental, podemos servir-nos do registro, onde a atividade do aluno é organizada, aparecendo os conhecimentos já adquiridos, apresentando-os em forma de relato, de descrição, busca de dados, observação real, experimentação... A partir desta organização 
ROCKENBACH \& RAMPELOTTO, vol.(4), ${ }^{\circ}$ 4, p. 730-748, 2011. Monografias Ambientais $\quad$ (e-ISSN: 2236-1308)

REMOA

devemos sempre desenvolver situações de análise, pelo debate crítico, comparações, ordenações, inferências, busca de novos dados e construir metas a serem atingidas.

A Educação Ambiental deve ser um processo contínuo e cíclico, que busca desenvolver os projetos, ações, bem como cursos capacitação e orientação de professores e cidadãos que conjugam os princípios gerais básicos do ensino e orientação das concepções socioambientais e suas coresponsabilidades.

Portanto, a Educação Ambiental propõe a quebra de fronteiras entre as disciplinas e subverte a lógica dicotômica que separa a cultura popular da cultura de elite, a cultura da natureza, a cultura da política e outras disjunções do pensamento moderno. Assim, convida-nos a pensar nos múltiplos espaços/tempos de formação em que o saber é construído.

Portanto, considero que os objetivos do estudo foram alcançados, pois, teve engajamento dos educadores, educandos e da comunidade, bem como as ações desenvolvidas na comunidade em parceria com a escola para a redução dos problemas ambientais causados a partir do desenvolvimento da resposabilidade socioambiental na comunidade.

\section{REFERÊNCIAS}

ALMEIDA, L. M. A. E ROGOLIN T. B., Geografia, Série Novo Ensino Médio, Editora Ática, 2a edição, 2004.

BARRETO, Alcyrus Vieira Pinto; HONORATO, Cezar de Freitas. Manual de sobrevivência na selva acadêmica. Rio de Janeiro: Objeto Direto, 1998.

BLACKING, J. 1995b "Music, Culture, and Experience", in: Music, Culture, and Experience: Selected Papers of John Blacking, Chicago/Londres, The University of Chicago Press, pp. 223-42. [Links]

CARVALHO, Janete Magalhães. Desafios à ciência e às políticas de desenvolvimento regional. Reflexões e recomendações sobre o futuro desenvolvimento da Amazônia. Estudos Avançados, v.3, n.7, p. 183-199, 1990.

pública. In:

Do projeto às estratégias/táticas de professores como profissionais necessários aos espaços/tempos da escola 10-44.

Educativa em Questão. Série cadernos de Reflexão. Instrumentos Metodológicos II. : Espaço Pedagógico. 2a ed. São Paulo: 1996.

FREIRE, Paulo, Pedagogia da autonomia: Saberes necessários à prática educativa. São Paulo: Paz e Terra, 1996.

GALIAZZI, M. C. et. Al. Construindo Caleidoscópios: organizando unidades de aprendizagem. Revista eletrônica do Mestrado de Educação Ambiental, Rio Grande, v. 09, p. 98 -111, jul. - dez. 2002.

GIL, Antonio Carlos. Como elaborar projetos de pesquisa. $4^{\mathrm{a}}$ ed. São Paulo: Atlas, 2002.

GIORDANO, G. Avaliação ambiental de um balneário e estudo de alternativa para controle da poluição utilizando o processo eletrolítico para o tratamento de esgotos. Niterói - RJ, 1999. 137 p. Dissertação de Mestrado (Ciência Ambiental) Universidade Federal Fluminense, 1999.

GIROUX, Henry. Atos impuros: a prática política dos estudos culturais. Porto Alegre: Artmed, 2003.

GUIMARÃES, M. Educação ambiental crítica. In: LAYRARGUES, Philippe (Org.). Identidades da educação ambiental brasileira. Brasília: Ministério do Meio Ambiente/ Diretoria de Educação Ambiental, 2004. 
ROCKENBACH \& RAMPELOTTO, vol.(4), n $^{\circ}$, p. 730-748, 2011. Monografias Ambientais $\quad$ (e-ISSN: 2236-1308)

REMOA

htpp://pt.wikipedia.org.br/wiki/Protocolo_de_Quioto/, Disponível em 17 de abril de 2010, às 15h.

http://novaescola.abril.uol.com.br/ed, Disponível em 11 de abril de 2010, às 14h.

http://pessoal.educacional.com.br/up/4770001/1306260/t137.asp

http://www.apromac.org.br/ea005.htm

http://www.folhadirigida.com.br/professor2001/cadernos/explosao/63.html disponível em 13/04/10 às 12h30min.

http://www.jornaldedebates.ig.com.br/index, díponível em 13 de abril de 2010, às 13h.

http://www.unimep.br/phpg/editora/revista/imp30art01.pdf.

IBAMA, Avaliação de Impacto Ambiental: agentes sociais, procedimentos e ferramentas. Brasília: IBAMA, 1995.

IMHOFF, K.; IMHOFF, K. R. Manual de Tratamento de Águas Residuárias. São Paulo: Edgard Blücher, 1996. Impactos regionais de "grandes projetos" e as possibilidades de reorganização do espaço na periferia amazônica. In: ARAGON, L.E. (ed.) A desordem ecológica da Amazônia. Série Cooperação Amazônica 7, UNAMAZ, p. 253-269, 1991.

KRAEMER, Maria Elisabeth Pereira - beth.kraemerarrobaterra.com.br

LAKATOS, Eva Maria; MARCONI, Marina de Andrade. Metodologia do Trabalho Científico, 4o ed., Atlas: 1995.

LAYRARGUES, Philippe (Org.). Identidades da educação ambiental brasileira. Brasília: Ministério do Meio Ambiente/Diretoria de Educação Ambiental, 2004.

LIBANEO, José Carlos. Organização e Gestão da Escola. Editora Alternativa, 2004.

LOUREIRO, Carlos Frederico Bernardo. Educação ambiental transformadora. In: www.scielo.com.br/educação33ambiental/tranformação.pdf, disponível em 23 de março de 2010.

MACEDO, Jorge A. B. Águas \& Águas. São Paulo: Varela, 2001.

MELCHIOR, Maria Celina. O Sucesso Escolar através da Avaliação e da recuperação. Novo Hamburgo: s/ed., 1998.

MINISTÉRIO DA EDUCAÇÃO E CULTURA. Parâmetros curriculares nacionais: temas transversais. Brasília: Secretaria de Educação Fundamental, 1998.

MORAES, José Geraldo Vinci de, História Geral e Brasil - Ensino Médio, Editora Atual, 1a Ed. São Paulo. 2003.

MORAES, M. C. Recuo da Teoria: Dilemas Na Pesquisa Em Educação. In: Intelectuais, Conhecimento E Espaço Público; Anais da 24a Reunião Anual Da Anped. Caxambú, Anped, 2001.

MORIN, Edgar. O método: a natureza da natureza. 3. ed. Portugal: Publicações Europa-América Ltda., 1977.

NUNES, J. A. Tratamento Físico-Químico de Águas Residuárias Industriais. Aracajú: ed. do autor. 1996.

OLIVEIRA, A. I. A. O Licenciamento Ambiental. São Paulo: IGLU, 1998.

OLIVEIRA, E. M. de. Educação Ambiental - Uma possível abordagem. 2ạ. Ed. Brasília: Ed. Ibama 2000. 
ROCKENBACH \& RAMPELOTTO, vol.(4), $\mathbf{n}^{\circ} 4$, p. 730-748, 2011. Monografias Ambientais $\quad$ (e-ISSN: 2236-1308)

REMOA

PARO, Vitor Henrique. Gestão democrática da escola pública. São Paulo, Ática, 1997.

. Práticas pedagógicas, profissão docente e formação: perspectivas sociológicas. Lisboa: Dom Quixote, $1993 a$.

PINEAU, Gaston. Temporalidades na formação. São Paulo: Triom, 2003.

ROESCH, Sylvia Maria Azevedo. Projetos de estágio do curso de administração: guia para pesquisas, projetos, estágios e trabalhos de conclusão de curso; Colaboração: Grace Vieira Becker e Maria Ivone de Mello. São Paulo: Atlas, 1996.

ROMÃO, José Eustáquio. Avaliação Dialógica: desafios e perspectivas. 2 ed. São Paulo: Cortez: Instituto Paulo Freire, 1999.

SANTOS, Boaventura de Souza. A crítica da razão indolente: contra o desperdício da experiência. 2. ed. São Paulo: Cortez, 2000.

SATO, M. Educação Ambiental. São Carlos: Rima, 2002.

SILVA, Manoel O. S. Alvares. Análises físico-químicas para controle de estações de tratamento de esgotos. Ed. Alternativa, 1998.

SILVA, Salomão A.; MARA, David D. Lagoas de estabilização. Rio de Janeiro: ABES, 1979. p.67.

TRIPODI John, graduate of Annunciation BVM School in Philadelphia, PA is on Classmates.com. Get caught up with John and other high, 1981- disponível em - www.spoke.com/dir/p/tripodi/john

TRIVIÑOS, A. N. S. Introdução à pesquisa em ciências sociais: a pesquisa qualitativa em educação. São Paulo: Atlas , 1987.

www.centrorefeducacional.com.br/gestdemaut.htm - acesso dia 13/04/10 ás 13h40min.

www.centrorefeducacional.com.br/gestdemaut.htm. Escola e Cultura: as bases sociais e epistemológicas do conhecimento escolar. Porto Alegre: Artes Médicas, 1993. Disponível em 17 de abril de 2010, às 18h15min.

www.centrorefeducacional.com.br/gestdemaut.htm. Introdução à psicologia escolar. 2.ed. São Paulo: T.A.Queiróz, 1986. Diponível em 17 de abril de 2010, às 16h12min.

www.centrorefeducacional.com.br/gestdemaut.htm. Vigiar e punir: nascimento da prisão. Trad. Raquel Ramalhete. 11a ed. Petrópolis: Vozes, 1994. 277p.

www.profissãomestre.com.br, Disponível em 20 de abril 2010, às 18h30min.

www.programapostural.com.br. Disponível em 17 de abril de 2010, às 15h35min.

YIN, Robert K. Estudo de Caso: Planejamento e Métodos. São Paulo: Bookman, 2001 